\title{
Effect of Scanning Speed on the Surface Roughness of Laser Metal Deposited Copper on Titanium Alloy
}

\author{
Mutiu Folorunsho Erinosho ${ }^{*}\left(\mathbb{0}^{-}\right.$, Esther Titilayo Akinlabi ${ }^{b}$, Oluwagbenga Temidayo Johnson $^{c, d}$ \\ ${ }^{a}$ Department of Mechanical and Industrial Engineering, University of Namibia, P.O. Box 3624, \\ Ongwediva, Namibia \\ ${ }^{b}$ Department of Mechanical Engineering Science, University of Johannesburg, Auckland Park Kingsway \\ Campus, Johannesburg, South Africa \\ 'Department of Metallurgy and Mining Engineering, University of Namibia, P.O. Box 3624, Ongwediva, \\ Namibia \\ ${ }^{d}$ Department of Metallurgy, School of Mining, Metallurgy and Chemical Engineering, Faculty of \\ Engineering and the Built Environment, University of Johannesburg, P.O. Box 17011, Doornfontein \\ 2028, South Africa
}

Received: April 16, 2019; Revised: July 03, 2019; Accepted: August 21, 2019

This paper reports on the effect of scanning speed on the laser deposited $\mathrm{Cu}$ on titanium alloy substrate. The experiments were conducted by varying the scanning speed from $0.3 \mathrm{~m} / \mathrm{min}$ to $1.2 \mathrm{~m} /$ min while the laser power, the powder feed rate and the gas flow rate were kept constant. The laser deposited $\mathrm{Cu}$ were characterized through the evolving microstructure and surface roughness. Dendrites and acicular were much pronounced in the clad area; found to decrease as the scanning speed increases due to the laser interaction time and the cooling rate. These however, influenced the irregularities in the peaks and valleys of the surface texture. The arithmetic mean deviation, Ra were measured and abridged from $6.70 \mu \mathrm{m}$ to $1.41 \mu \mathrm{m}$ as the scanning speed was increased from samples DC1 to DC4. The motivation for this work is to improve the surface performance of Ti6Al4V alloy when exposed and attacked by marine microfouling organisms.

Keywords: Laser metal deposition, microstructure, pure Cu deposition, Ti6Al4V alloy substrate, surface roughness.

\section{Introduction}

Laser Metal Deposition (LMD) is known as the process of using a laser beam of high intensity to create a melt pool on a metal substrate; and in which powders were deposited to form the clad and fusion bond. Finished and semi-finished engineering components have been fabricated with the application of powder metallurgy principle ${ }^{1}$. Ti6Al4V alloy belongs to the group of advanced materials with their application in the aerospace ${ }^{2}$. The strength of the alloy with the addition of $\mathrm{Cu}$ was improved by utilizing the precipitation hardening technique ${ }^{3}$. Cu has been reported to have a low chemical reaction in moist air ${ }^{4}$, and thus, is a strong $\beta$-stabilizing element, and its atomic migration into titanium lattice results in the formation of beta titanium ${ }^{5}$. Its corrosion resistance and antimicrobial effect make it ideal for brewing vessels ${ }^{6}$. The interlayer of copper has been used to subdue the interflow of titanium; thus this in turn overpowers the formation of brittle intermetallics ${ }^{7}$. The sputtering of titanium films were deposited on three different substrates which includes copper, glass and silicon substrates at a temperature of $473 \mathrm{~K}$ for 3 hours each in order to optimize the process parameters. No voids were observed at the thickness of the coatings between the interface of the titanium film and the substrate. The coatings on the copper substrate were even as compared to other substrates but the deposition did not show preferred orientation and intensity ${ }^{8}$. Graded interface was developed

*e-mail: mutiuerinosho1@gmail.com by depositing a thin copper layer on titanium alloy (Ti6Al4V) substrate prior to several laser cladding of cobalt on it. The application of $\mathrm{Cu}$ interlayer on the alloy of titanium prior to laser cladding with cobalt has caused the formation of a number of intermetallics between copper and titanium, essentially, $\mathrm{Cu}_{3} \mathrm{Ti}$ and $\mathrm{CuTi}_{3}$, and subdues the formation of $\mathrm{Ti}_{2} \mathrm{Co}$ completely ${ }^{9}$. $\mathrm{Cu}$ has been deposited on steel from a solution of $\mathrm{Cu}$ (II) complex by electro-deposition process. A homogenized $\mathrm{Cu}$ coating was made with good and poor adhesion. This however depends on the rate of cementation ${ }^{10}$. The influence of microstructural behaviour of $\mathrm{H} 13$ steel on high strength $\mathrm{Cu}$ substrate has been reported. The adhesion between the deposited steel and $\mathrm{Cu}$ in the first layer was more distinct in the melt pool ${ }^{11}$. In application, $\mathrm{Cu}$ stabilizes the conductor material and leads to an improvement in the technical and practical performance during electroplating pulse laser deposition ${ }^{12}$. For many years, the problem faced by titanium alloy has been the issue of biofouling; and this has always been a major dilemma, which occurs in the marine industries. The $\mathrm{Cu}$ is an important trace element for marine organisms and is found naturally at low concentrations in the aquatic environment. It is considered as one of the most toxic heavy metals to marine invertebrates of several trophic groups. It has also been shown to decrease the reproductive success, growth rates and abundance of many species ${ }^{13}$. The $\mathrm{Cu}$-Ti binary phase diagram entails six diverse compounds, $\mathrm{Cu}_{4} \mathrm{Ti}_{1} \mathrm{Cu}_{2} \mathrm{Ti}_{1} \mathrm{Cu}_{3} \mathrm{Ti}_{2}, \mathrm{Cu}_{2} \mathrm{Ti}_{3}, \mathrm{CuTi}$ and $\mathrm{CuTi}_{2}$ respectively. It was reported from a phase diagram that at low temperatures, 
about $873.15 \mathrm{~K}$, a finite solid solubility for titanium in copper occurs but no solubility for copper in titanium. This however indicated that the copper can only diffuse in titanium through the grain boundaries or through compound formation. This copper however, can be used for power devices due to the ability to electro-migrate ${ }^{14}$.

This paper reports the effect of scanning speed on the laser metal deposited $\mathrm{Cu}$ and Ti6Al4V alloy with potential for marine application. The scanning speeds are varied from $0.3 \mathrm{~m} / \mathrm{min}$ to $1.2 \mathrm{~m} / \mathrm{min}$ while the laser power, the powder flow rate and the gas flow rate were kept constant.

\section{Experimental set up}

The experiment was conducted on the Ytterbium laser system equipment (YLS-2000-TR) at the National Laser Centre, Council for Scientific and Industrial Research (NLCCSIR), Pretoria, South Africa. The equipment is powered at $2.0 \mathrm{~kW}$ (maximum) and supported with a Kuka robot for the deposition process. The laser beam passes through the centre of a three way nozzle while the powder flows through the coaxially three ways outlet as shown in Figure 1.

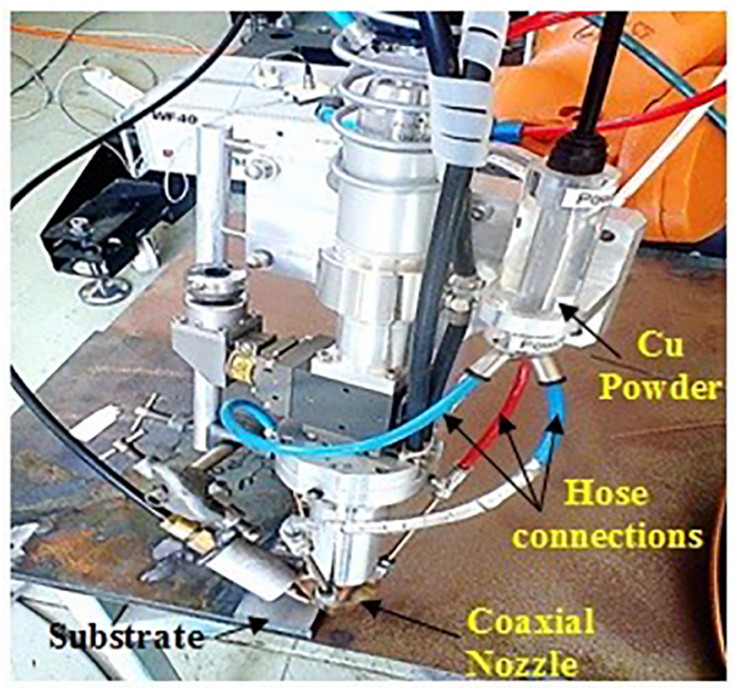

Figure 1. Schematic view of the nozzle head ${ }^{15}$

The nozzle is connected to a laser robotic arm. Both the powder and the laser beam were ejected at the end of the nozzle and laser deposit on the substrate to form the solidified metal. Pure $\mathrm{Cu}$ powder and Ti6Al4V alloy substrate were used for the laser experiment. The $\mathrm{Cu}$ powder is fed via a hopper - a powder feeder capillary which is connected to the nozzle via long hoses. The particle sizes of the pure $\mathrm{Cu}$ powder are between 100 and $200 \mu \mathrm{m}$. The argon gas was supplied at $10 \mathrm{l} / \mathrm{min}$ to provide a shield for the deposited $\mathrm{Cu}$ during the operation so as to prevent oxygen contamination.

A square plate of Ti6Al4V alloy was used as the substrate. It was sand blasted to purify the surface and to prepare it for metallographic bonding. The blasted surface was cleaned with acetone and dried off.
The process parameters used for the experiment are presented in Table 1.

Table 1. Experimental matrix

\begin{tabular}{lcc}
\hline Samples Name & $\begin{array}{c}\text { Laser Power } \\
(\mathbf{k W})\end{array}$ & $\begin{array}{c}\text { Scanning Speed } \\
(\mathbf{m} / \mathbf{m i n})\end{array}$ \\
\hline DC1 & 1.2 & 0.3 \\
DC2 & 1.2 & 0.5 \\
DC3 & 1.2 & 0.9 \\
DC4 & 1.2 & 1.2 \\
\hline
\end{tabular}

The beam diameter of $4 \mathrm{~mm}$ and the standoff distance between the nozzle tip and the substrate is kept at $12 \mathrm{~mm}$. The powder flow rate and the gas flow rate used for the $\mathrm{Cu}$ powder of $2.0 \mathrm{rpm}$ and $2.0 \mathrm{l} / \mathrm{min}$ are kept constant. The deposited samples were wire brushed and labelled from DC1 to DC4. All the samples were ground and prepared for metallography according to the E3-11 ASTM standard ${ }^{16}$. Two separate reagents were prepared for the etchants. One was prepared for the $\mathrm{Cu}$ deposits while the other etchant for the Ti6Al4V alloy substrate. The reagent for the Ti6Al4V alloy substrate is prepared with $\left(100 \mathrm{ml} \mathrm{H}_{2} \mathrm{O}, 2 \mathrm{ml} \mathrm{HF}, 4 \mathrm{ml}\right.$ $\mathrm{HNO}_{3}$ ) and the reagent for the deposited $\mathrm{Cu}$ is prepared with ( $5 \mathrm{ml}$ distilled $\mathrm{H}_{2} \mathrm{O}, 5 \mathrm{ml} \mathrm{NH}_{3}$ solution, $3 \mathrm{ml} \mathrm{H}_{2} \mathrm{O}_{2}$ ). These were prepared according to the metallographic preparation ${ }^{17}$, and also in order to observe the microstructural grains of the $\mathrm{Cu}$ deposit and the substrate.

The Scanning Electron Microscopy (SEM) analyses were conducted on the $\mathrm{Cu}$ powder and the lateral surface of the laser deposited $\mathrm{Cu}$ after hot-mounted in polyfast. A TESCAN machine equipped with VEGA TC software was used for the analyses. The surface roughness of the deposited surface was measured using the HOMMELETAMIC TURBO WAVE V7.53 machine. The machine is equipped with a TKU600 probe with a measuring range of $160 \mu \mathrm{m}$ that scans through the surface of the deposited samples. The coarse levelling was first done on the surface of the sample after the area of focus has been noticed, and then positioned it for measuring. As the stage is moving with the stylus tip on the sample's surface, a trace is being generated on the screen.

\section{Results and Discussion}

The morphology of the $\mathrm{Cu}$ powder observed under the SEM indicates spherical particles with uneven sized structure as shown in Figure 2. The $\mathrm{Cu}$ powder was processed by atomisation method and the powder particles were well densely packed.

The SEM microstructures of laser deposited samples DC1 to DC4 observed at 1000x magnification are presented. Figures 3 (a) to (d) show the microstructures of samples DC1 to DC4 deposited at constant laser power of $1.2 \mathrm{~kW}$ and varying scanning speeds from $0.3 \mathrm{~m} / \mathrm{min}$ to $1.2 \mathrm{~m} / \mathrm{min}$ respectively. 


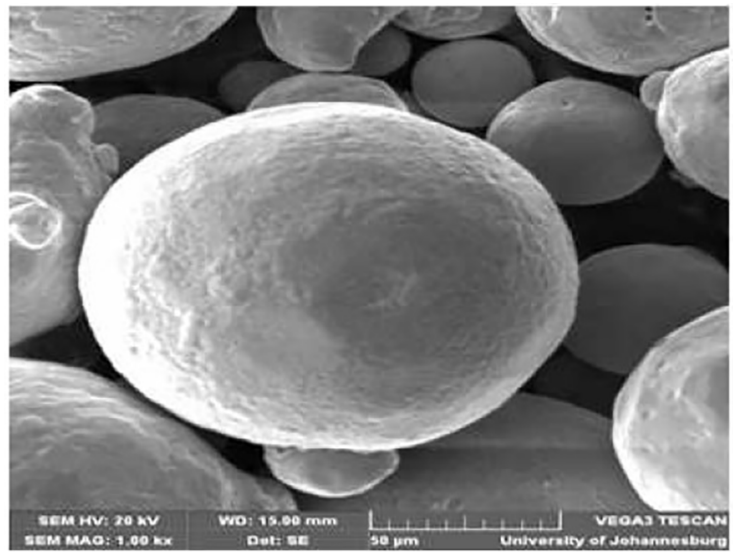

Figure 2. SEM morphology of $\mathrm{Cu}$ powder.
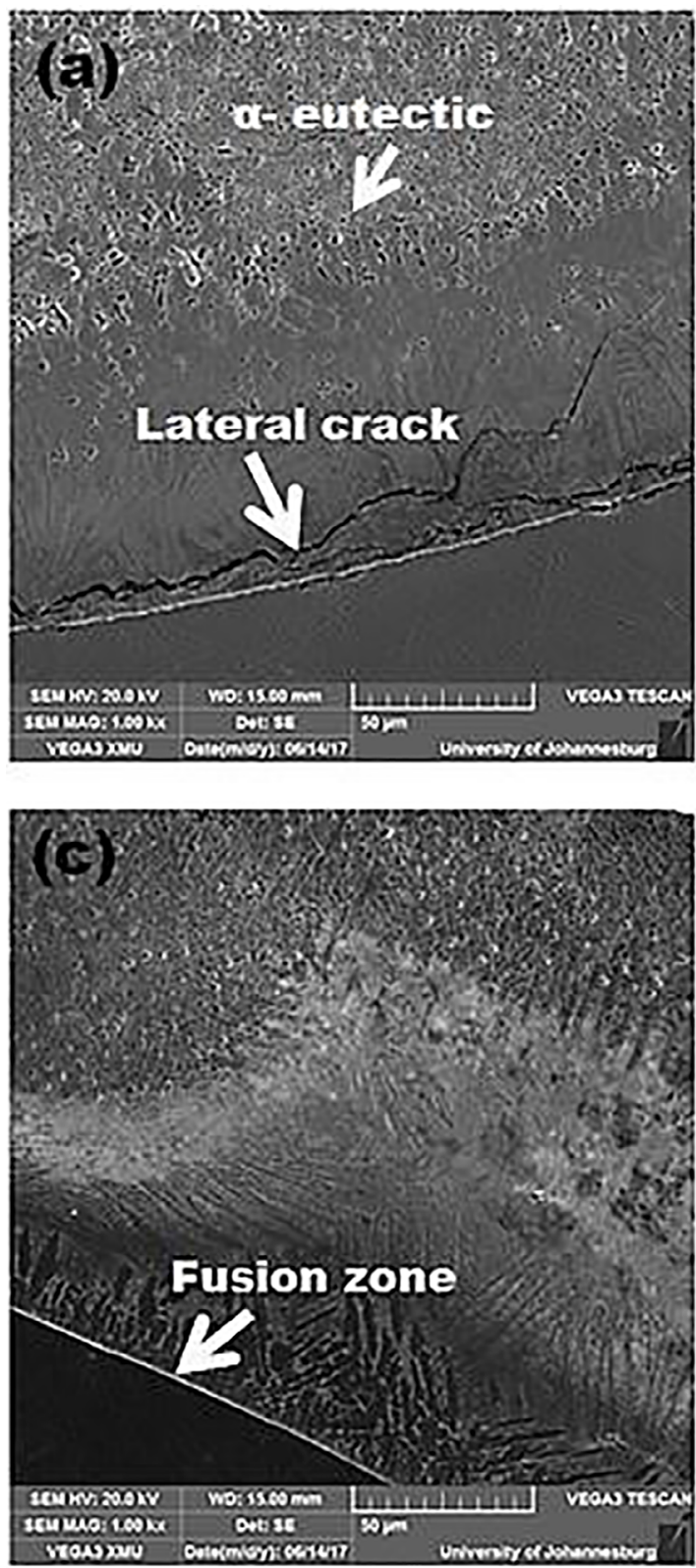

The melt pool created on the substrate allows the adhesion of $\mathrm{Cu}$ powder in it. Dendrites of $\mathrm{Cu}$ were observed in most of the cladded layer and were also found reducing in thickness as the scanning speed was increased. This is as a result of the decrease in the laser interaction time with the substrate during the deposition of the $\mathrm{Cu}$ powder. There are three arms of dendrites formed, the main arms, the auxiliary arms and the trivial arms. The main arm shows a structural rise from the inner region of a dendrite arm to the outer surface which can be corroborated with Scott ${ }^{18}$, thereby serving as the central pillar for other dendrites. The slow cooling rate at low scanning speed is accountable for the evidence of structural dendrite arms, and found to be invisible at high scanning speed ${ }^{18}$ due to the limited interaction time during
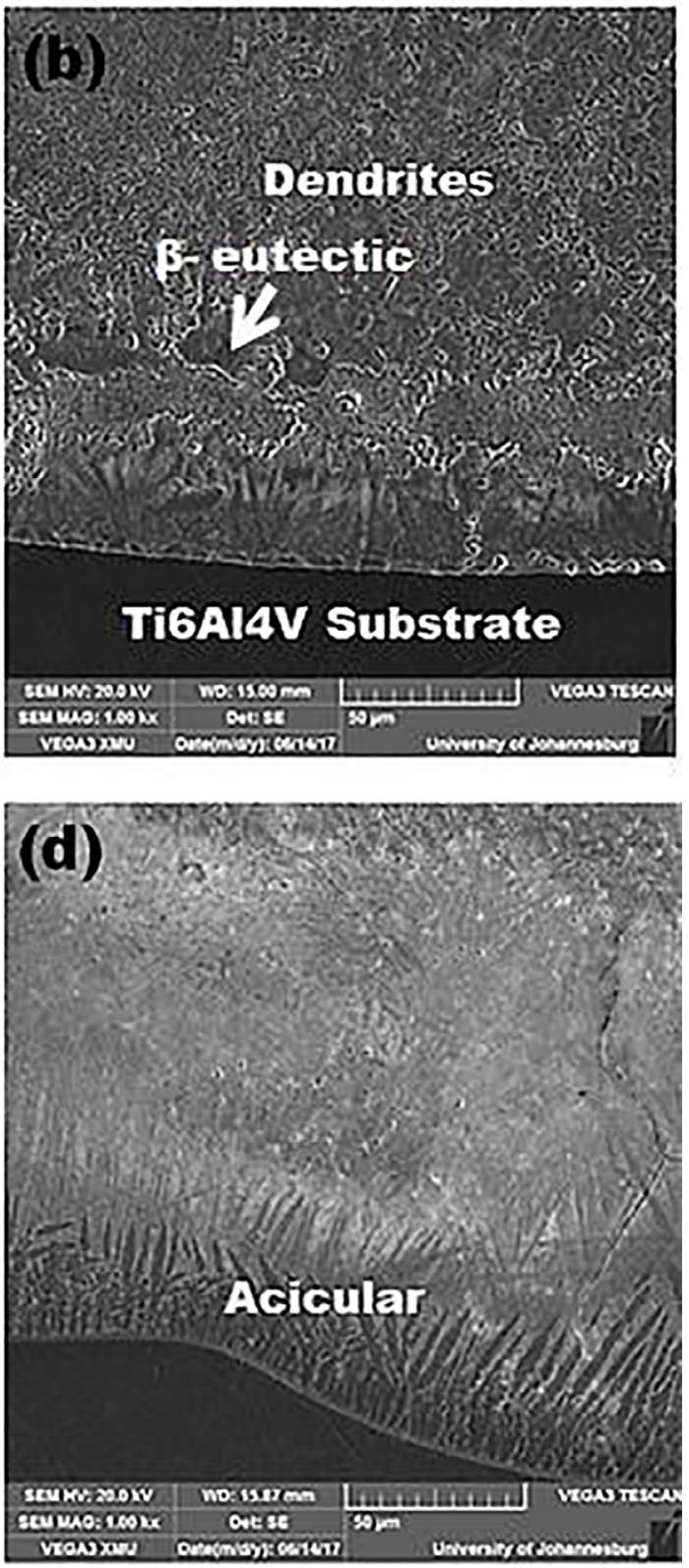

Figure 3. SEM microstructures of deposited samples (a) DC1 deposited with a scanning speed of $0.3 \mathrm{~m} / \mathrm{min}$, (b) DC2 deposited with a scanning speed of $0.5 \mathrm{~m} / \mathrm{min}$, (c) DC3 deposited with a scanning speed of $0.9 \mathrm{~m} / \mathrm{min}$, (d) DC4 deposited with a scanning speed of $1.2 \mathrm{~m} / \mathrm{min}$. 
the deposition process. The main dendrites in Figure 3 (a) of sample DC1 deposited at laser power of $1.2 \mathrm{~kW}$ and scanning speed of $0.3 \mathrm{~m} / \mathrm{min}$ were growing thicker with shorter growths of the trivial arms. A decrease in the cooling rate of the copper matrix formed leads to the growth of dendrites and grains ${ }^{19}$. The melt pool created with the scan speed of $0.3 \mathrm{~m} / \mathrm{min}$ is enough to accommodate the volume of $\mathrm{Cu}$ deposited powder and to give good bonding but since the wettability between the deposited $\mathrm{Cu}$ powder and the Ti6Al4V alloy substrate is truncated at slow scanning speed, then good bonding is limited. Pin-like acicular microstructures were formed arbitrarily towards the fusion zone between the deposited $\mathrm{Cu}$ and the Ti6Al4V alloy substrate. The dissipation of thermal energy from the melted $\mathrm{Cu}$ in the substrate as well as the low thermal retention of the titanium alloy has resulted in the acicular grains formed. However, this attribute leads to the lateral cracks observed immediately after the fusion zone of sample DC1. The difficulty of copper to diffuse into titanium has been reported and it can only be done through the grain boundaries ${ }^{19}$. As the scanning speed was increased to $0.5 \mathrm{~m} / \mathrm{min}$ in sample DC2, fragments of dendrites were densely formed towards the midway of the $\mathrm{Cu}$ deposit. Similarly, the acicular structures towards the fusion zone were becoming stronger. As the scanning speed increases further, the dendrites of the main and auxiliary arms disappear; thereby forming armless dendritic structures. The fading away of the dendrite structures were observed in sample DC3 deposited with a scanning speed of $0.9 \mathrm{~m} / \mathrm{min}$ when the scanning speed continues to increase. At sample DC4 deposited with a laser power of $1.2 \mathrm{~kW}$ and scanning speed of $1.2 \mathrm{~m} / \mathrm{min}$, new solidification sites are formed at this stage, and as such causing the formed $\alpha / \beta$ eutectic structure to be vanishing as the dendrite arm disappears. This is as a result of the high cool rate that exists between the deposited interfaces. The fast laser interaction time between the laser beam, the $\mathrm{Cu}$ powder and the substrate has a significant effect on the behaviour of the microstructure at highest scanning speed used.

Figures 4 (a) to (d) show the surface roughness measurements for the laser deposited $\mathrm{Cu}$ samples from $\mathrm{DC} 1$ to DC4 respectively at varying scanning speed from $0.3 \mathrm{~m} /$ $\min$ to $1.2 \mathrm{~m} / \mathrm{min}$.

The contact between the stylus tip and the surface of the laser deposited samples measures the surface texture and create the surface profiles as shown in Figures 4 (a) to (d) with different surface roughness values. The mean line is measured at the zero ( 0 ) point on the y-axis. For all the samples, the amplitude parameters such as the arithmetic mean deviation $\mathrm{R}_{a}$, and the maximum height $\mathrm{R}_{z}$ of the roughness profiles are measured. The roughness and the degree of waviness determine the texture of the laser deposited surface. The waviness defers from length to length, and shows some bumpy profiling as the scanning speed was increased for every sample. The time of interaction of the laser beam and
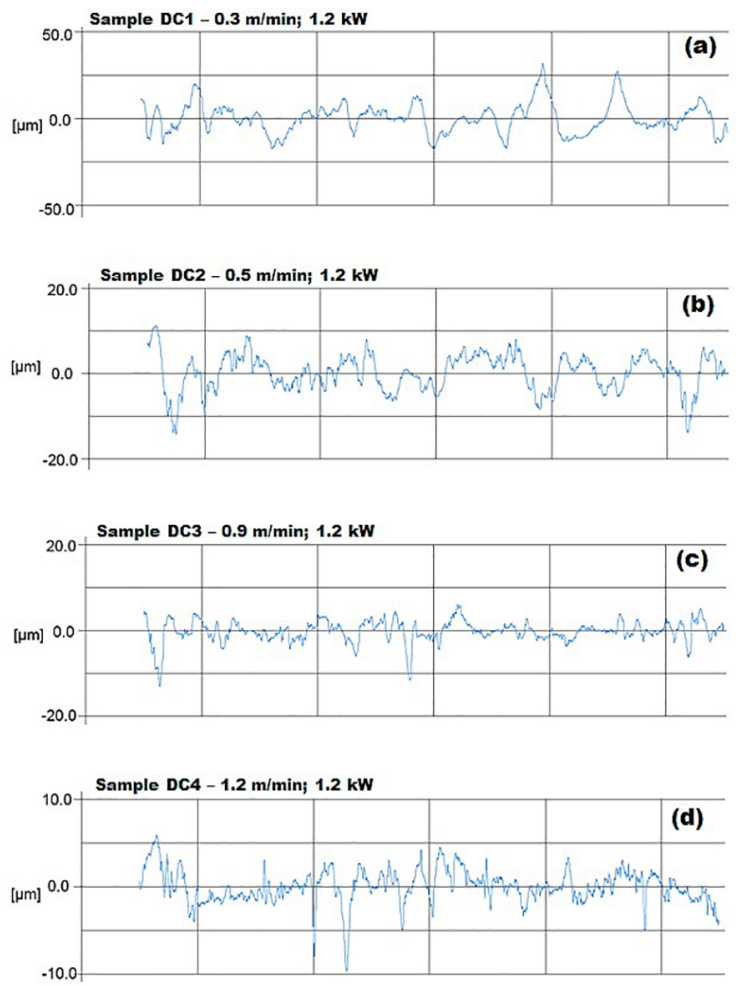

Figure 4. Surface roughness measurements for the laser deposited Cu samples; (a) DC1 deposited with a scanning speed of $0.3 \mathrm{~m} / \mathrm{min}$, (b) DC2 deposited with a scanning speed of $0.5 \mathrm{~m} / \mathrm{min}$, (c) DC3 deposited with a scanning speed of $0.9 \mathrm{~m} / \mathrm{min}$, (d) DC4 deposited with a scanning speed of $1.2 \mathrm{~m} / \mathrm{min}$.

the cooling rate during the deposition process influence the irregularities in the peak and valley of the surface texture. The roughness height and width decrease from sample DC1 to DC4 as the scanning speed was increased. The tallest peaks above $25 \mu \mathrm{m}$ occur in sample DC1 deposited at a scanning speed of $0.3 \mathrm{~m} / \mathrm{min}$. However, high scanning speed induced between the laser beam and the $\mathrm{Cu}$ powder gives a good surface roughness. A better surface texture can still be achieved if the laser power is increased from the $1.2 \mathrm{~kW}$ used in this experiment. This was reported in an experiment conducted by Mahamood and Akinlabi ${ }^{20}$. As the laser power was increased in their experiment, the surface roughness results achieved were found to diminish. This was due to the fact that an increase in the laser power can create suitable melting of the deposited powder and can amount to a smoother surface ${ }^{20}$. A large melt-pool created as a result of increased laser power during laser deposition process can improve the surface finish of the deposited specimen ${ }^{21}$.

Figure 5 shows the plot of the arithmetic mean deviation $\mathrm{R}_{a}$, the maximum height $\mathrm{R}_{z}$ and the highest peak $\mathrm{R}_{\max }$ of the surface roughness for the samples from DC1 to DC4 respectively.

The arithmetic mean is the universally recognized parameter of surface roughness, and it is measured from the mean line of the profile. Similarly, if the randomness of 


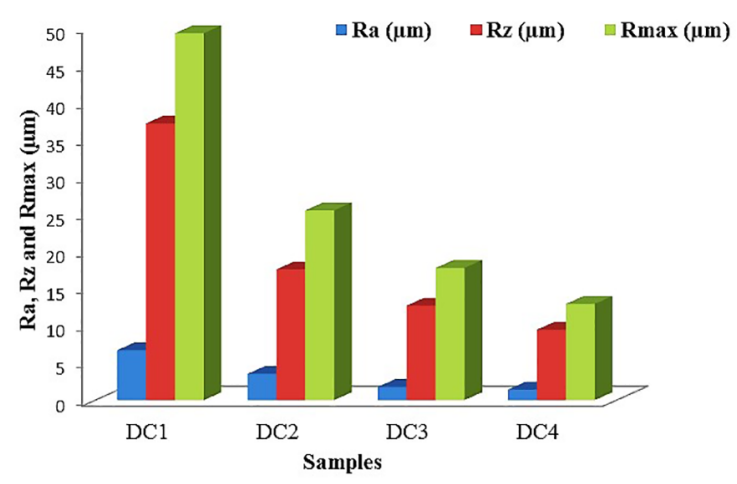

Figure 5. Plot of the arithmetic mean deviation $\mathrm{R}_{a}$, the maximum height $\mathrm{R}_{z}$ and the highest peak $\mathrm{R}_{\max }$ of the surface roughness.

the roughness level is high compared to the top of the peak, then the highest peak of $\mathrm{R}_{\max }$ or the maximum height of $\mathrm{R}_{z}$ must be measured ${ }^{22}$.

Figure 6 shows the definitions of some parameters employed for the roughness profile.

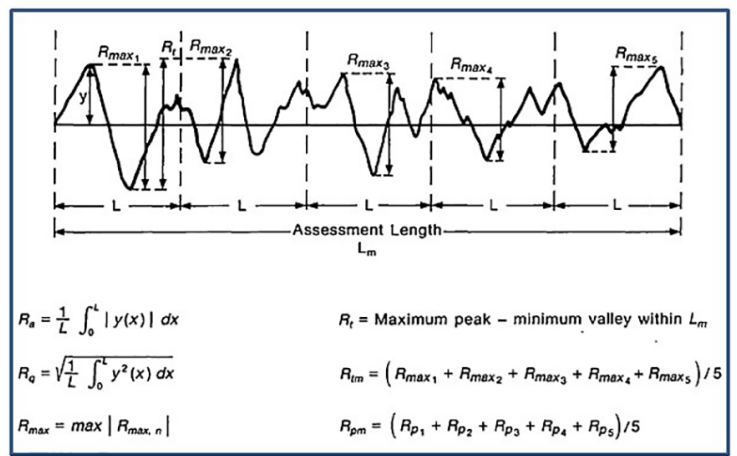

Figure 6. Definitions of some commonly used roughness parameters ${ }^{22}$

The profile of the arithmetic mean must be filtered with a distinct cut-off filter prior to calculating the parameters. This is actually done to avoid the influence of long wavelength components known as waviness ${ }^{22}$. However, this automatically fixes the mean line between the profiling. The $\mathrm{R}_{a}(\mathrm{~s})$ for all the deposited samples from DC1 to DC4 are $6.7 \mu \mathrm{m}, 3.52 \mu \mathrm{m}, 1.77 \mu \mathrm{m}$ and $1.41 \mu \mathrm{m}$ respectively. The $\mathrm{R}_{z}$ (s) for the samples are $37.15 \mu \mathrm{m}, 17.55 \mu \mathrm{m}, 12.69$ $\mu \mathrm{m}$ and $9.46 \mu \mathrm{m}$ respectively while the $\mathrm{R}_{\max }(\mathrm{s})$ are 49.26 $\mu \mathrm{m}, 25.49 \mu \mathrm{m}, 17.75 \mu \mathrm{m}$ and $12.92 \mu \mathrm{m}$ respectively. The $\mathrm{R}_{a}$, $\mathrm{R}_{z}$ and $\mathrm{R}_{\max }$ experience a fall in the roughness values in all the laser deposited samples from DC1 to DC4 respectively. Among the entire participating specimen, sample DC1 deposited at a scanning speed of $0.3 \mathrm{~m} / \mathrm{min}$ exhibits that highest $\mathrm{R}_{a}, \mathrm{R}_{z}$ amd $\mathrm{R}_{\max }$ of $6.7 \mu \mathrm{m}, 37.15 \mu \mathrm{m}$ and 49.26 $\mu \mathrm{m}$ respectively. At high scanning speed, the bumpiness of the peaks and valleys widens compare to other profiles due to the energy density and intensity of the laser beam. The slow depositing interaction time has contributed to more bulk of the deposit, and this however contributes to the high surface texture measured.

\section{Conclusions}

Despite the low wettability characteristics possessed by copper with titanium alloy during fusion, the depositions through laser process have been greatly achieved. In the SEM analyses conducted, the three dendrite arms, acicular microstructure as well as the alpha and beta eutectic structures were revealed on the characterized specimens. The new solidification sites formed at high scanning speed caused the already formed $\alpha / \beta$ eutectic structure to be disappearing with the loss of the dendrite arms. The sample deposited with the highest scanning speed of $1.2 \mathrm{~m} / \mathrm{min}$ exhibits the lowest surface roughness with $\mathrm{R}_{a}, \mathrm{R}_{z}$ and $\mathrm{R}_{\max }$ values of $1.41 \mu \mathrm{m}$, $9.46 \mu \mathrm{m}$ and $12.92 \mu \mathrm{m}$ respectively as a result of the swift interaction time between the laser beam-powder deposition and the substrate used. Further work needs to be carried out on the corrosion behaviour of the samples for marine application in order to combat the problem of biofouling.

\section{Acknowledgement}

This research work was supported by the National Research Foundation (NRF), Pretoria, South Africa and the National Commission on Research Science and Technology (NCRST), Windhoek, Namibia on a collaborative project.

\section{References}

1. A Global Market Review IPMD. $15^{\text {th }}$ ed. 2012-2013. Available from: http://www.ipmd.net/shop/powder_metallurgy

2. Froes HF, Yau TL, Weidinger HG. Titanium, Zirconium and Hafnium. In: Matucha KH, Weinheim VCH, editors. Structure and Properties of Nonferrous Alloys. Amsterdam: Materials Science and Technology; 1996. p. 401.

3. Gollapudi S, Sarkar R, Babu UC, Sankarasubramanian R, Nandy TK, Gogia AK. Microstructure and mechanical properties of a copper containing three phase titanium alloy. Materials Science and Engineering: A. 2011;528(22-23):6794-6803.

4. Lenntech BV. Water Treatment Solution [Internet]. Miami Beach, FL: Lenntech; 1998-2013. Available from: www.lenntech.com/ periodic/element/Ti.

5. Ghosh M, Chatterjee S. Diffusion bonded transition joints of titanium to stainless steel with improved properties. Material Science Engineering: A. 2003;358(1-2):152-158.

6. Copper Development Association-Coper Alliance. About Cooper - Cooper and Cooper Alloys [Internet]. Hemel Hempstead, UK: Cooper Alliance; 2012. Available from: http://www. copperalliance.org.uk/copper-and-itsalloys/alloys/coppers

7. Massalski TB, Okamoto H, Subramanian PR, Kacprzak L. Binary Alloy Phase Diagrams. 2a ed. Ohio, USA: ASM International; 1990.

8. Dasgupta A, Singh A, Parida PK, Ramaseshan R, Kuppusami $\mathrm{P}$, Saroja S, et al. Structural characteristics of titanium coating on copper substrates. Bulletin of Materials Science. 2011;34(3):483-489. 
9. Majumdar JD. Direct laser cladding of cobalt on Ti-6Al-4V with a compositionally graded interface. Advances in Materials Science and Engineering. 2011;509017:[aprox.4 telas]. DOI: https://doi.org/10.1155/2011/509017

10. Spasoevic M, Cvijovic M, Rybic-Zelenovic L, Ac'amovicJokovic G. Electrochemical deposition of copper on steel from a solution of diacido-1,3-propylenediamine- $N, N$ '-diacetato$N, N$ '-dipropionate cuprate(II). Russian Journal of Applied Chemistry. 2007;80(4):566-70.

11. Khalid MI, Masood SH, Brandt M. Microstructural investigation of direct metal deposition of H13 steel on high strength copper substrate. In: Proceedings of the World Congress on Engineering; 2009 jul. 1-3; London, UK. London, UK: WCE; 2009. v. 1.

12. Floegel-Delor U, Riedel T, Wippich D, Goebel B, Rothfeld R, Schirrmeister P, et al. Reel-to-reel copper electroplating on pulse laser deposition coated conductor. IEEE Transactions on Applied Superconductivity. 2011;21(3):2984-7.

13. Hall Junior LW, Scott MC, Killen WD. Ecological risk assessment of copper and cadmium in surface waters of Chesapeake Bay watershed. Environmental Toxicology and Chemistry. 1998;17(6):1172-1189.

14. Castoldi L, Visalli G, Morin S, Ferrari P, Alberici S, Ottaviani $\mathrm{G}$, et al. Copper-titanium thin film interaction. Microelectronic Engineering. 2004;76(1-4):153-159.

15. Erinosho MF, Akinlabi ET, Pityana SL. Influence of Scanning Speed and Energy Density on the Evolving Properties of Laser Deposited Ti6Al4V/Cu Composites. In: Proceedings of the World Congress on Engineering; 2015 jul. 1-3; London, UK. London, UK: WCE; 2015. v. 2.
16. ASTM - American Society for Testing and Materials. E3-11 Standard Guide for Preparation of Metallographic Specimens. West Conshohocken, USA: ASTM; 2013.

17. Struers - Ensuring Certainty. Application Note Titanium [Internet]. Cleveland, USA: Struers Inc.; 2019. Available from: http://www.struers.com/resources/elements/12/104827/ Application_Note_Titanium_English.pdf

18. Scott DA. Metallography and Microstructure of Ancient and Historic metals. Marina del Rey, CA: Getty Conservation Institute and Archetype Books; 1991.

19. Martyushev N. Parameters of the dendritic structure of copper alloys. Chemistry of Metals and Alloys. 2010;3:197-200.

20. Mahamood RM, Akinlabi ET. Effect of laser power on surface finish during laser metal deposition process. In: Proceedings of the World Congress on Engineering and Computer Science; 2014 oct. 22-24; San Francisco, USA. San Francisco, USA: WCECS; 2014. v. 2.

21. Gharbi M, Peyre P, Gorny C, Carin M, Morville S, Le Masson $\mathrm{P}$, et al. Influence of various process conditions on surface finishes induced by the direct metal deposition laser technique on a Ti-6Al-4V alloy. Journal of Materials Processing Technology [Internet]. 2012; 213(5):791-800. Available from: https://ff10.1016/j.jmatprotec.2012.11.015ff.ffhal-00987226f

22. Brüel, Kjær. Technical review to advance techniques in acoustical, electrical and mechanical measurement - Surface Roughness Analysis. 1983;(3):1-48. 